\title{
Artificial light emission analysis for the city of St. Petersburg
}

\author{
Svetlana Kolgushkina ${ }^{1}$ \\ ${ }^{1}$ ITMO University, School of Photonics, Faculty of Laser and Light Engineering, Department of \\ Creative Lighting Design, St. Petersburg, Russia
}

\begin{abstract}
Artificial light emission within the limits of major cities is increasing year by year. The level of this rapid growth depends on the influence of complex factors such as urban enlargement, air pollution, environmental conditions, lack of outdoor lighting master-planning, etc. Continuing monitoring of sky glow changes is an important part of the lighting environment's complex analysis. This paper estimates the contribution of 18 districts of St. Petersburg to the glow between 2014 and 2017, evaluated with the use of Garstang's model and GIS-based analysis of VIIRS data. The dynamic changes in sky brightness show a significant increase in the anthropogenic sky glow over three years.
\end{abstract}

\section{Introduction}

The influence of urban lighting on night sky brightness has been studied since 1970s. The first model for a sky brightness estimation was Walker's model [1]. Walker's law is described by the equation (1), considering the population size and the distance of the observer from the city.

$$
B=C P D^{-2,5}
$$

where $P$ is the population, $D$ is the distance of the observer from the city, $B$ is an increase in the sky brightness related to natural sky glow, and $C$ is the coefficient dependent on such factors as light emission per capita and the reflection coefficient of the ground surface.

A more complex model of sky brightness estimation, which took into account the approximation for small angles and considered the mechanisms of particle dispersion, was proposed by Bertiau and Treanor [2]. Treanor's model was modified by Garstang [3,4,5] to consider the heterogeneity of the atmosphere. In the modified model, the density of molecules and aerosols in the atmosphere exponentially decreases with altitude increase. Garstang's model showed itself as responsive in many American observatories. Since 2001, satellites have been used to analyse artificial night sky brightness. This research was first published by P. Cinzano, F. Falchi and C. D. Elvidge.

\footnotetext{
${ }^{1}$ Corresponding author: svkolgushkina@corp.ifmo.ru
} 
The problem of artificial light emission growth has traditionally been tackled by astrophysicists and astronomers. Yet experts from other related fields have been lately paying increasing attention to this problem.

From the lighting design perspective, artificial light emission analyses are very important to monitor annual augmentation in order to protect the environment from the further growth of sky glow caused by artificial lighting in the cityscape. This is especially important for countries without control over the minimization of light pollution.

\section{Field of study}

Despite the importance of limiting artificial light emission, this question has not been sufficiently studied in Russia. A lack of specific requirements, which would limit and regulate the work of lighting designers, amplifies the problem.

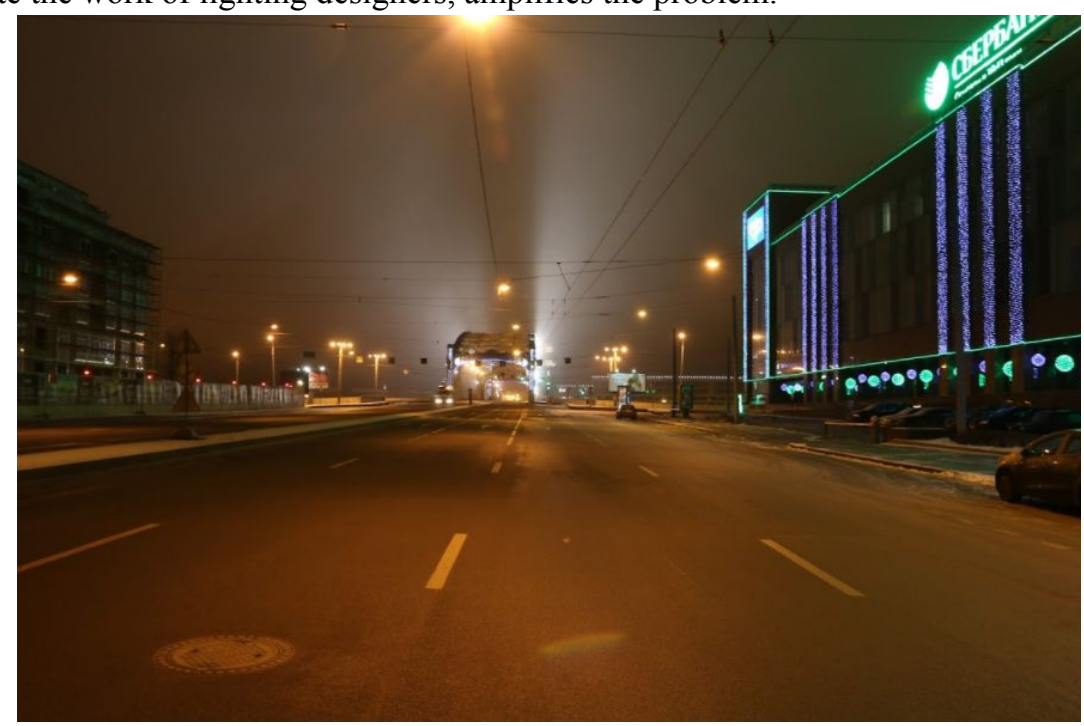

Figure 1. An example of a low-quality lighting solution.

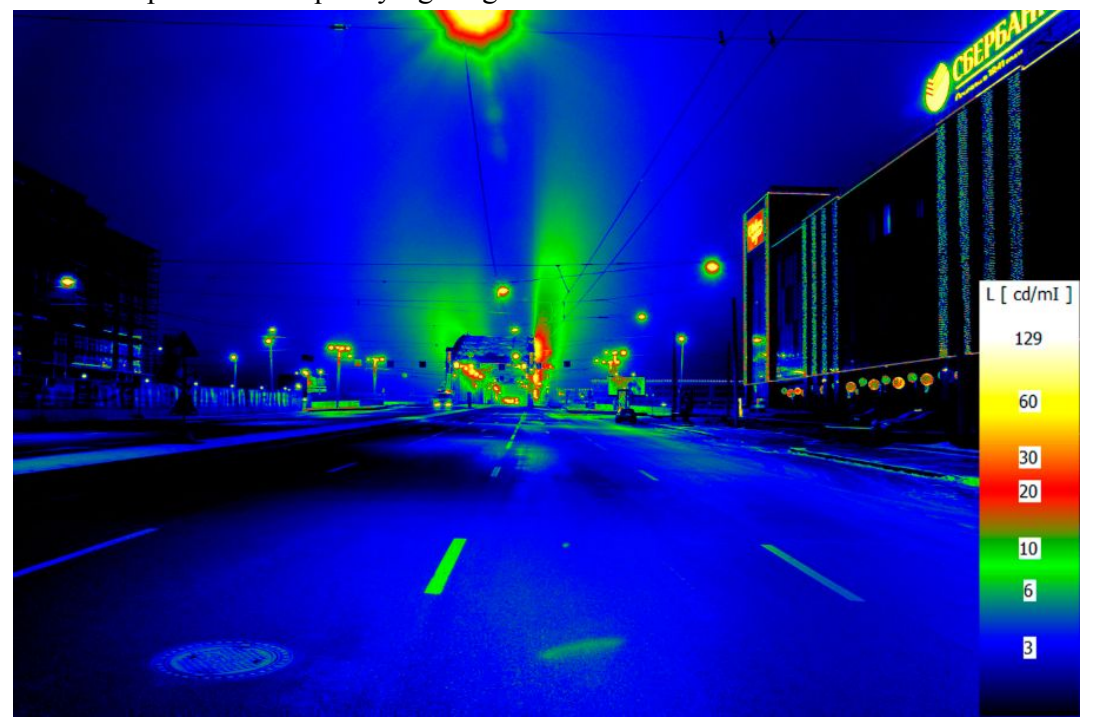

Figure 2. Luminance distribution, measured by using a luminance measuring imaging photometer. 
Changes in the number of light fixtures between 2014 to 2017 is shown in Table 1.

Table 1. The number of light fixtures (Data source: State Unitary Enterprise Lensvet)

\begin{tabular}{|c|c|c|c|}
\hline Year & $\begin{array}{c}\text { Number of } \\
\text { fixtures }\end{array}$ & $\begin{array}{c}\text { Number } \\
\text { of poles }\end{array}$ & $\begin{array}{c}\text { Objects } \\
\text { with arch. } \\
\text { lighting }\end{array}$ \\
\hline $\mathbf{2 0 1 4}$ & 215319 & 78508 & 427 \\
\hline $\mathbf{2 0 1 7}$ & 257600 & 97696 & 445 \\
\hline
\end{tabular}

Table 2. The share of light fixtures in 2017 (Data source: State Unitary Enterprise Lensvet)

\begin{tabular}{|c|c|c|}
\hline $\begin{array}{c}\text { Types of light } \\
\text { sources }\end{array}$ & $\begin{array}{c}\text { \% of the } \\
\text { total }\end{array}$ & \% of capacity \\
\hline HPS lamps & 65.4 & 87.6 \\
\hline $\begin{array}{c}\text { Metal halide } \\
\text { lamps }\end{array}$ & 26.6 & 10.3 \\
\hline LED lamps & 8.44 & 1.94 \\
\hline
\end{tabular}

The number of lighting fixtures grew by 42,000 units between 2014 and 2017. In view of these significant changes, the analysis of dynamic artificial light emission is of utmost importance.

In the Russian Federation, there are no laws, codes or standards, which would regulate light pollution. The number of buildings and constructions with architectural lighting in big cities in Russia is very high, compared with European countries. To raise the issue of light quality, we evaluated sky glow progression in the period between 2014 and 2017.

\section{Methodology}

In our study, we used artificial sky brightness modelling principles formulated by Garstang. In total, 18 districts of St. Petersburg were considered separately and included in the research study.

Garstang's model offers a two-component composition of the atmosphere [4,5]:

- molecular components of the atmosphere, which particle density at $\mathrm{h}$ height above the sea level is described by the equation:

$$
N_{1}(h)=N_{m} \cdot e^{-c(h)}
$$

where $N_{m}=2.55 \cdot 10^{19} \mathrm{sm}^{3}$ is the particle density at sea level, $c=0.104 \mathrm{~km}^{-1}$ according to Allen

- aerosol particles, which density at h height is:

$$
N_{2}(h)=N_{a} \cdot e^{-a \cdot h}
$$

where $N_{a}=2.55 \cdot 10^{19} \mathrm{sm}^{3}$ is the density of aerosol particles at ground level, $a=0.657+0.059 \mathrm{~K}$ is the approximation based on McClatchey data, K indicates the quality of the atmosphere. [4,5]

The equations 3 and 4 may be used with the following assumptions:

- molecules in the atmosphere are in hydrostatic equilibrium

- density of aerosol is the exponential function 
- the atmosphere is horizontally homogeneous

The absorption in the lower layers of the atmosphere for vertical distribution of particles is represented by the Lambert-Beer law.

$$
\tau(h)=\int_{0}^{h} k d h=N_{m} \cdot \sigma_{m} \cdot\left[\left(1-e^{-c h}\right) c^{-1}+11.778 K\left(1-e^{-a^{\prime} h}\right)\right]
$$

where $k=N_{m} \cdot \sigma_{m}+N_{a} \cdot \sigma_{a}, \quad \sigma_{m}$ is cross section of the molecules, $\sigma_{a}$ is cross-section of aerosol particles.

The model considers Rayleigh scattering of molecules in the atmosphere with the cross-section of $\sigma_{R}=4.6 \times 10^{-27} \mathrm{sm}^{2}$ for the $550 \mathrm{~nm}$ wavelength for visible observations. Multiple scattering of molecules and aerosol particles is described by the equation:

$$
\operatorname{SAA}(\omega)=N_{m} \sigma_{m}\left(11.778 K \frac{\left\{1-e^{-a s c o s} \psi\right.}{a}+\gamma \frac{\left\{1-e^{-\operatorname{cscos} \psi}\right\}}{c}\right) \cos \psi^{-1}
$$

where $\gamma$ is the Garstang factor to account for the spherical nature of Rayleigh scattering compared to aerosol scattering [4,5].

According to Garstang's model, artificial light emission intensity distribution in the upper hemisphere is described by the equation:

$$
I_{u p}=\frac{L P}{2 \pi} \cdot\{2 G(1-F) \cdot \cos \psi+0.554 \cdot F \cdot \psi\}
$$

where $G$ is the surface albedo, $F$ is the proportion of the luminous flux emitted by light fixtures into the upper hemisphere, $P$ is the population, $L$ is luminous flux per capita.

Luminous flux per capita was estimated based on statistical data on lighting equipment provided by State Unitary Enterprise Lensvet. The population size of 18 districts was evaluated in accordance with Federal State Statistics Service data.

In the equation (6), the albedo of the earth's surface was set $\mathrm{G}=0.15$, and the proportion of the luminous flux emitted by lamps into the upper hemisphere is $\mathrm{F}=0.13$.

The basic equation of the sky brightness model is:

$$
b=\pi \cdot I_{u p}(\psi) \cdot S^{-2} \cdot \int d u \cdot e^{-\tau(S)} \cdot(1+S A A) \cdot e^{-\tau(u)}
$$

The formula for the transition to photometric units, accepted in astronomy, is as follows:

$$
V=41.438-1.0857 \cdot \ln (b)
$$

For GIS-based analysis, we used different layers of information about St. Petersburg, such as residential population data, Visible Infrared Imaging Radiometer Suite (VIIRS) data on radiance provided by the Earth Observation Group, and National Geophysical Data Center (NOAA) collected by Jurij Stare. 


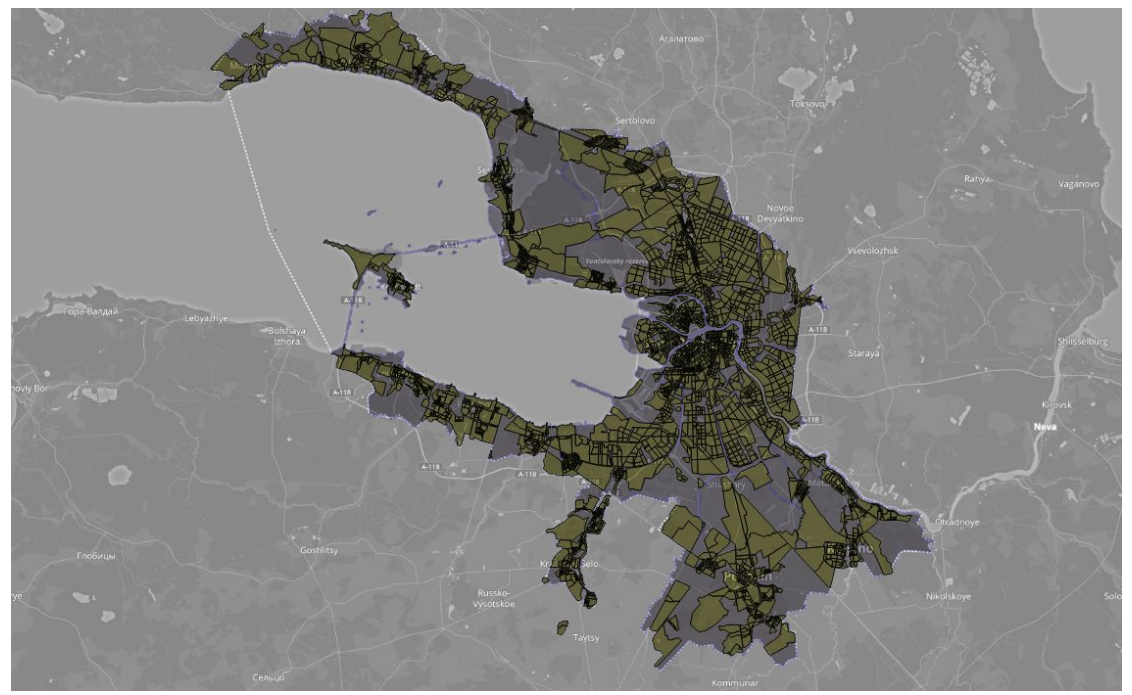

Figure 3. The residential population data layer.

\section{Results}

The largest contribution to the increase in the sky brightness in St. Petersburg is made by the following regions: Kalininsky, Primorsky, Vyborgsky, and Nevsky.

The artificial light emission data obtained for all districts are shown in Figure 4 and Table 3.

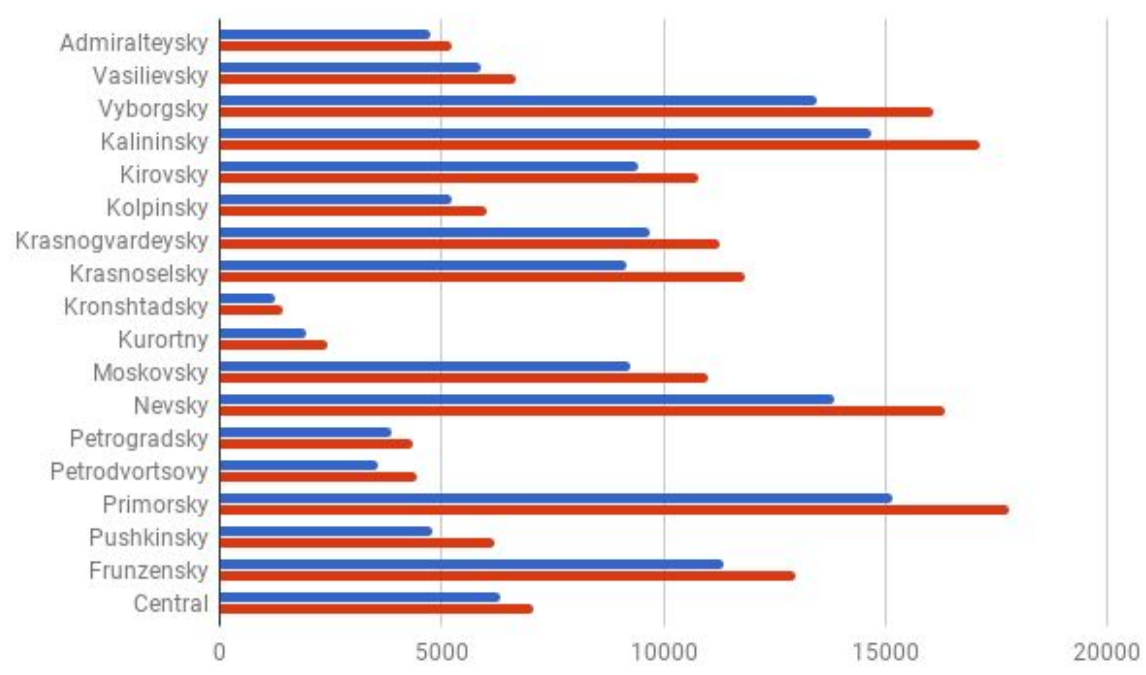

Figure 4. The artificial light emission data obtained for all districts of St. Petersburg based on Garstang's model for the years 2014 (blue bars) and 2017 (red bars).

Table 3. The population and artificial light emission intensity for 18 districts of St. Petersburg.

\begin{tabular}{|l|l|l|l|l|}
\hline \multirow{2}{*}{ District } & \multicolumn{2}{|c|}{2014} & \multicolumn{2}{c}{2017} \\
\cline { 2 - 5 } & P, thousands of & $I_{u p}$, cd & P, thousands of & $I_{u p}$, cd \\
\hline
\end{tabular}




\section{LIGHTING DESIGN 2017}

\begin{tabular}{|c|c|c|c|c|}
\hline & people & & people & \\
\hline Admiralteysky & 171 & 4762 & 164 & 5242 \\
\hline Vasilievsky & 211 & 5875 & 209 & 6694 \\
\hline Vyborgsky & 483 & 13449 & 502 & 16096 \\
\hline Kalininsky & 527 & 14674 & 536 & 17134 \\
\hline Kirovsky & 339 & 9439 & 337 & 10776 \\
\hline Kolpinsky & 187 & 5207 & 188 & 6003 \\
\hline Krasnogvardeysky & 348 & 9690 & 352 & 11250 \\
\hline Krasnoselsky & 330 & 9189 & 370 & 11833 \\
\hline Kronshtadsky & 44 & 1225 & 44 & 1423 \\
\hline Kurortny & 70 & 1949 & 76 & 2434 \\
\hline Moskovsky & 333 & 9272 & 344 & 11006 \\
\hline Nevsky & 498 & 13869 & 512 & 16368 \\
\hline Petrogradsky & 139 & 3870 & 136 & 4340 \\
\hline Petrodvortsovy & 128 & 3564 & 138 & 4420 \\
\hline Primorsky & 544 & 15147 & 556 & 17772 \\
\hline Pushkinsky & 172 & 4789 & 193 & 6182 \\
\hline Frunzensky & 408 & 11360 & 406 & 12993 \\
\hline Central & 227 & 6320 & 220 & 7047 \\
\hline
\end{tabular}

The results of the GIS-based analysis for the period between 2014 and 2017 are shown in Figure 5 and Figure 6. 
Figure 5. Artificial light emission data obtained for all districts of St. Petersburg based on 2014 statistical data.

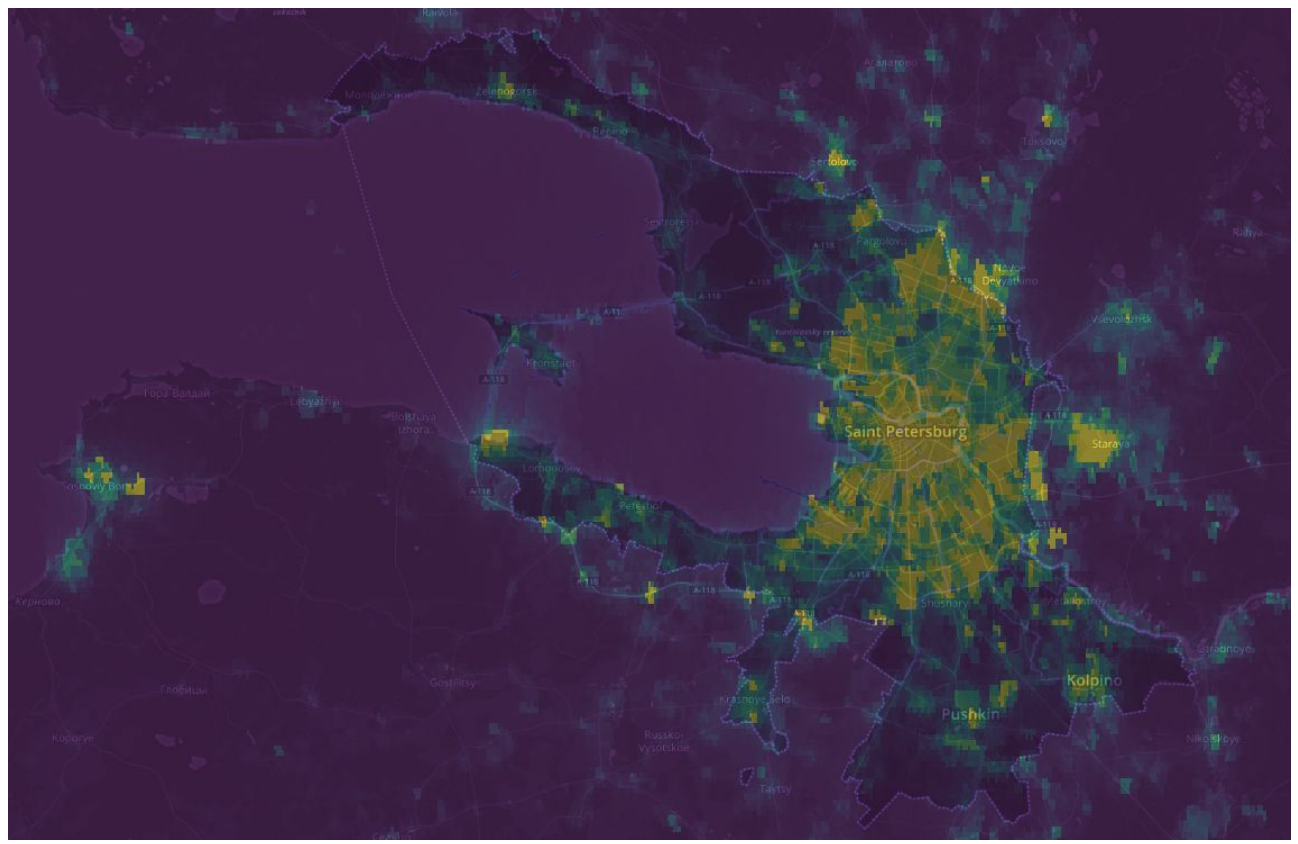

Figure 6. Artificial light emission data obtained for all districts of St. Petersburg based on 2017 statistical data.

\section{Conclusion}


Artificial light emission is growing very rapidly without any codes or laws which would help minimize light pollution. The attention of lighting designers should be focused on the quality of their work.

According to the definition of the Institution Lighting Professionals (ILP), any artificial light, which goes beyond the limits of the subject to illumination, including the light projected above the horizon into the night sky or creating glow danger, is considered undesirable and causes light pollution.

At present, some countries such as the Republic of Chile, Slovenia, Italy, the Czech Republic, parts of the United States of America and the United Kingdom have adopted a series of regulatory documents with the aim to reduce the anthropogenic component of sky glow.

To reduce the dynamics of the growth in anthropogenic component of sky glow, patterns of light propagation in the lower layers of the atmosphere and scattering type of various particles should be considered while design works. The reflected component of the light flux from the surfaces to be illuminated contributes significantly to sky glow. Therefore, light pollution can be reduced by optimizing the design of lighting systems, ensuring their compliance with acceptable levels of quantitative characteristics of lighting, performing installation control, and using lighting control systems.

\section{References}

1. Walker, M. F. The Effects of Urban Lighting on the Brightness of the Night Sky. Publ. Astron. Soc. Pacific 1977, 89, 405-409.

2. Bertiau, F. C., de Graeve, E. Treanor, P. J. The Artificial Night-Sky Illumination in Italy. Vatican Observatory Publ. 1973, 1, 159-179.

3. Garstang, R. H., Light Pollution Modeling, 1991 in Light Pollution, Radio Interference, and Space Debris, ISBN 0-937797-36-8; D.L. Crawford, Bookcrafters, Inc., 56-69.

4. Garstang, R. H. Model for Artificial Night-Sky Illumination. Publication of the Astronomical Society of the Pacific 1986, 98, 364-375.

5. Garstang, R. H. Night-Sky Brightness at Observatories and Sites. Publ. Astron. Soc. Pacific 1989, 101 306-329. 